\title{
Analysis of satellite measurements of ozone, nitrous oxide and methane: intra-annual variations in the stratosphere
}

\author{
ALEKSANDR N. GRUZDEV and IGOR I. MOKHOV
}

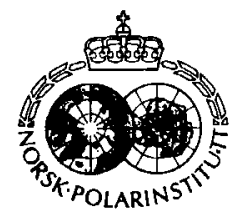

\begin{abstract}
Gruzdev, A. N. \& Mokhov, I. I. 1994: Analysis of satellite measurements of ozone, nitrous oxide and methane: intra-annual variations in the stratosphere. Polar Research 13, 13-22.

Peculiarities in the intra-annual variations of $\mathrm{O}_{3}, \mathrm{~N}_{2} \mathrm{O}$ and $\mathrm{CH}_{4}$ in the middle and upper stratosphere are analysed by different methods for the middle and polar latitudes of the Northern and the Southern hemispheres. In the middle stratosphere the phase of the $\mathrm{O}_{3}$ annual harmonic shifts in the Northern Hemisphere from polar to lower latitudes, while in the Southern Hemisphere the downward shift is exhibited. The phase of the $\mathrm{N}_{2} \mathrm{O}$ annual harmonic shifts to the poles both in the Northern and Southern hemispheres, but in the Northern Hemisphere it is almost vertical with the horizontal spreading, while in the Southern Hemisphere the phase propagation has a remarkable downward component. The most similar shifts of the phase of the annual harmonic in the middle stratosphere of both hemispheres are exhibited for the $\mathrm{CH}^{4}$ content in the middle and high latitudes. Remarkable differences are noted between the intervals with the increase of mixing ratios in the annual cycle at different latitudinal belts. In particular, these intervals are large in subtropical stratosphere, with a shorter and steeper decrease of the mixing ratios. The general decrease of these intervals is exhibited from middle to polar latitudes. The striking difference in temporal variations of the species exists between the northern polar and middle latitudes, where the month-to-month changes of the species are often opposite each to other. These peculiarities and interhemispheric differences are associated with the different stratospheric dynamics of the Northern and Southern hemispheres, particularly with different regimes of planetary wave activity in the northern and southern extratropical latitudes.
\end{abstract}

Aleksandr N. Gruzdev and Igor I. Mokhov, Institute of Atmospheric Physics, Russian Academy of Sciences, Pyzhevsky per. 3, Moscow 109017, Russia.

\section{Introduction}

Previous studies of the intra-annual variability in vertical distribution of ozone $\left(\mathrm{O}_{3}\right)$, nitrous oxide $\left(\mathrm{N}_{2} \mathrm{O}\right)$ and methane $\left(\mathrm{CH}_{4}\right)$ have been made by Wilcox et al. (1977), Jones \& Pyle (1984), Gray \& Pyle (1986), Solomon et al. (1986), Holton \& Choi (1988), Sun \& Leovy (1990) and Gruzdev et al. (1991). All three species are well observable from satellite. The annual and semiannual harmonics are known to be main contributors to the annual cycles of the species (Gruzdev \& Mokhov 1988; Holton \& Choi 1988). Although having different origins and different spatial and temporal distributions, these species have fairly long lifetimes (especially $\mathrm{CH}_{4}$ ) to be tracers of the transfer processes in the stratosphere. The aim of this paper is a joint analysis of intra-annual variations of the three species on a global scale, with emphasis on features of their behaviour in polar regions. Note that behaviour of $\mathrm{N}_{2} \mathrm{O}$ and $\mathrm{CH}_{4}$ at polar latitudes has not been analysed in previous studies.

\section{Data and methods}

Monthly mean, zonal mean satellite data for the middle and upper stratosphere (above $20 \mathrm{mb}$, approximately $28 \mathrm{~km}$ ) are analysed. The data are the four year (1978-1982) Nimbus 7 LIMS, Nimbus 7 SBUV and AE-2 SAGE ozone measurements in the latitude band of $80 \mathrm{~N}$ to $80 \mathrm{~S}$ reported by Keating \& Young (1985), and the three year (1979-81) Nimbus 7 SAMS measurements of $\mathrm{N}_{2} \mathrm{O}$ and $\mathrm{CH}_{4}$ in the latitude band of $70 \mathrm{~N}$ to $50 \mathrm{~S}$ reported by Taylor et al. (1987). For the analysis of the intra-annual evolution of $\mathrm{O}_{3}, \mathrm{~N}_{2} \mathrm{O}$ and $\mathrm{CH}_{4}$ in the middle and upper stratosphere, different methods of analysis are used. One is the standard harmonic analysis which makes the decomposition of a complicated annual cycle into the linear superposition of the annual harmonic, the semiannual harmonic, and so on.

Although characterisation of separate harmonics (by their amplitudes and phases) is sufficient for knowing not only the integral but also the local (in time) behaviour of harmonics, it is 
not a simple matter in the case of the complicated annual cycle. The presence of two (or more) harmonics in an annual cycle can make it asymmetric. Moreover, the behaviour of separate harmonics is not always associated with separate mechanisms. For an analysis of complicated cycles in atmospheric species' fields the special method of amplitude and phase characteristics can be used (Mokhov 1985). Useful characteristics of the asymmetry of the annual cycle are the interval of increase with the positive time derivative and the interval with the exceeding of the local annual mean values (mixing ratios). These intervals are integral characteristics of the annual cycle, while the harmonic analysis displays the behaviour of separate harmonics, which is only a part of the common behaviour (Gruzdev \& Mokhov 1988).

More detailed characteristics of the intraannual evolution of atmospheric components are exhibited by the intermonth variations. Here the month-to-month changes (MMCs) of mixing ratios (i.e., the differences between the mixing ratios for two successive months: the latter value minus the former value) will be used. The MMCs are very useful, as they give information on governing processes through the continuity equation.

\section{Results}

The latitude-height cross sections of the February ozone mixing ratios (ozone annual cycle is incomplete with winter data at the southern polar latitudes) and the mean square deviation of the ozone annual cycle, correspondingly, can be seen in Fig. $1 A$ and $B$. Fig. 2A and B and Fig. $3 A$ and $B$ show the annual mean mixing ratios of $\mathrm{N}_{2} \mathrm{O}$ and $\mathrm{CH}_{4}$ as well. Note that in Fig. 1B and in Figs. 2 and 3 the coverage is asymmetric about the equator.

According to Fig. 1B the ozone annual cycle has amplitude maxima in the upper and middle stratosphere at high and middle latitudes of both the Northern Hemisphere (NH) and Southern Hemisphere (SH). The maxima are noted approximately above and below the maximum in ozone vertical distribution (cf. Fig. 1A). The significant feature of the $\mathrm{N}_{2} \mathrm{O}$ and $\mathrm{CH}_{4}$ intraannual variability is exhibited in Figs. $2 \mathrm{~B}$ and $3 \mathrm{~B}$ by the two low-latitude maxima and the minimum at the $\mathrm{NH}$ middle latitudes at constant pressure surfaces. Both the $\mathrm{N}_{2} \mathrm{O}$ and $\mathrm{CH}_{4}$ mixing ratios decrease with height $\left(\mathrm{N}_{2} \mathrm{O}\right.$ decreases more rapidly) and have low-latitude maximum at constant pressure surfaces.
Fig. 4 shows the phases (time of maximum) of the annual and semiannual harmonics of $\mathrm{O}_{3}$; Figs. 5 and 6 show those of $\mathrm{N}_{2} \mathrm{O}$ and $\mathrm{CH}_{4}$. These figures include the $\mathrm{NH}$ polar latitudes compared with similar analysis by Holton \& Choi (1988). It is also worth noting that we use the data modified compared with those used by Holton \& Choi (1988). The maximum of the ozone annual harmonic appears in the middle stratosphere above the northern and southern polar regions in appropriate spring (Fig. 4A). In the NH middle stratosphere the $\mathrm{O}_{3}$ annual harmonic propagates from polar to lower latitudes, while in the $\mathrm{SH}$ the downward phase propagation occurs, with equator-ward component at middle latitudes. The maxima of both the $\mathrm{N}_{2} \mathrm{O}$ and $\mathrm{CH}_{4}$ annual harmonics appear at the $\mathrm{NH}$ polar latitudes in late spring (Figs. 5A and 6A). Both phases propagate from tropical to polar latitudes. Propagating to the south, the phases move simultaneously down in the SH extratropical latitudes. In the NH extratropical latitudes, however, the propagation of the phase of the $\mathrm{CH}_{4}$ annual harmonic has less downward component, and the phase of the $\mathrm{N}_{2} \mathrm{O}$ annual harmonic propagates to the north without downward component. Moreover, the tendency of upward $\mathrm{N}_{2} \mathrm{O}$ phase propagation in the highlatitude middle stratosphere is seen.

The phases of the semiannual harmonics of all three species propagate downward above the tropics (Figs. 4B, 5B and 6B), thus following the propagation of the regime of the well-known semiannual oscillation of the equatorial zonal wind (Gray \& Pyle 1986; Holton \& Choi 1988). In the $\mathrm{NH}$ high latitudes, equator-ward propagation of the phase of the semiannual harmonic of $\mathrm{O}_{3}$ occurs in the middle stratosphere, and equator-ward propagation of the phases of the semiannual harmonics of $\mathrm{N}_{2} \mathrm{O}$ and $\mathrm{CH}_{4}$ occurs in the upper stratosphere.

The largest intervals of increase for $\mathrm{N}_{2} \mathrm{O}$ and $\mathrm{CH}_{4}$ (up 8 months and larger) are exhibited in the subtropical stratosphere. The annual cycles of these components are characterised there by a shorter and steeper decrease of the mixing ratios with longer intervals of relatively slow increase. The stratospheric layers with a large intervals of increase are displayed in subtropical latitudes for the ozone content too. There is also general decrease of these intervals from middle to polar latitudes with a shorter and steeper increase of the mixing ratios in the annual cycle.

Fig. 7 shows the altitude-time cross-sections of 

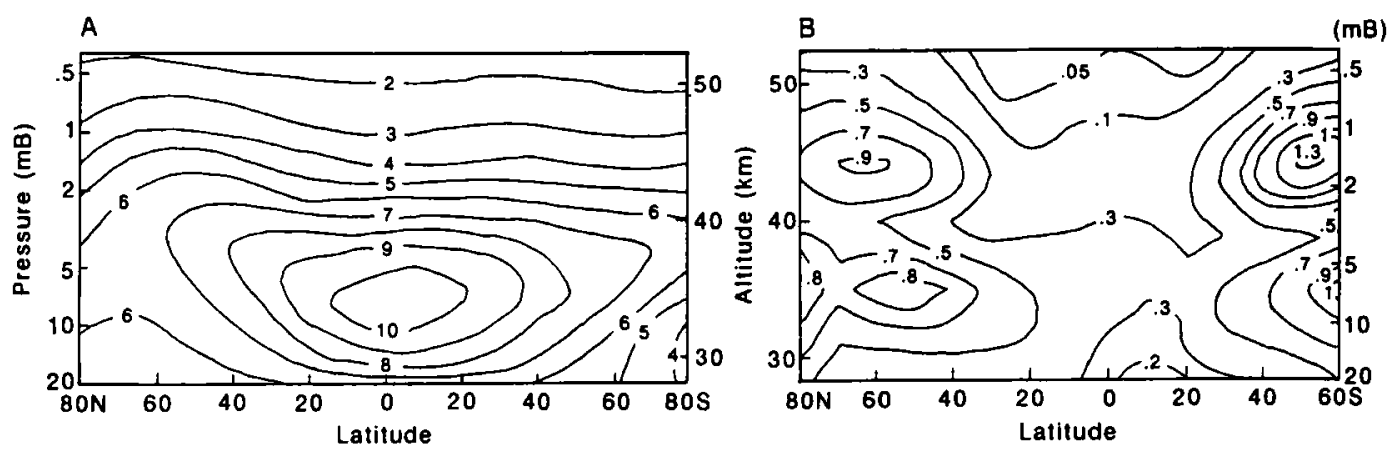

Fig. I. Latitude-height cross sections of (A) the $\mathrm{O}_{3}$ mixing ratios (ppmv) in February and (B) the mean square deviation of the $\mathrm{O}_{3}$ annual cycle (ppmv).
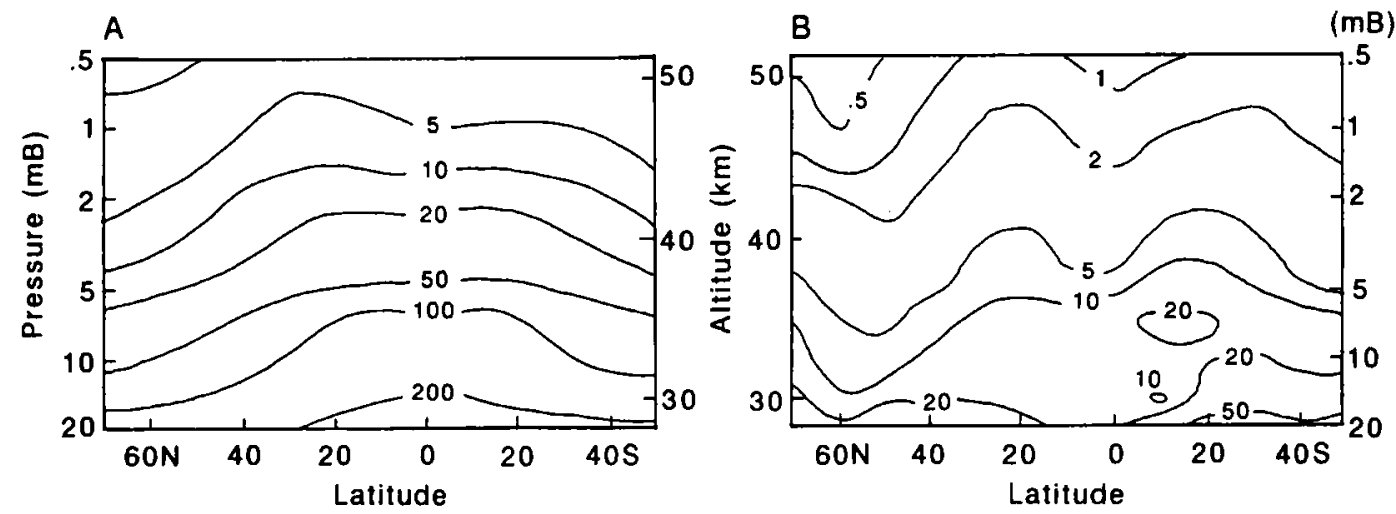

Fig. 2. Latitude-height cross sections of (A) the annual mean $\mathrm{N}_{2} \mathrm{O}$ (ppbv) and (B) the mean square deviation of the $\mathrm{N}_{2} \mathrm{O}$ annual cycle (ppbv).
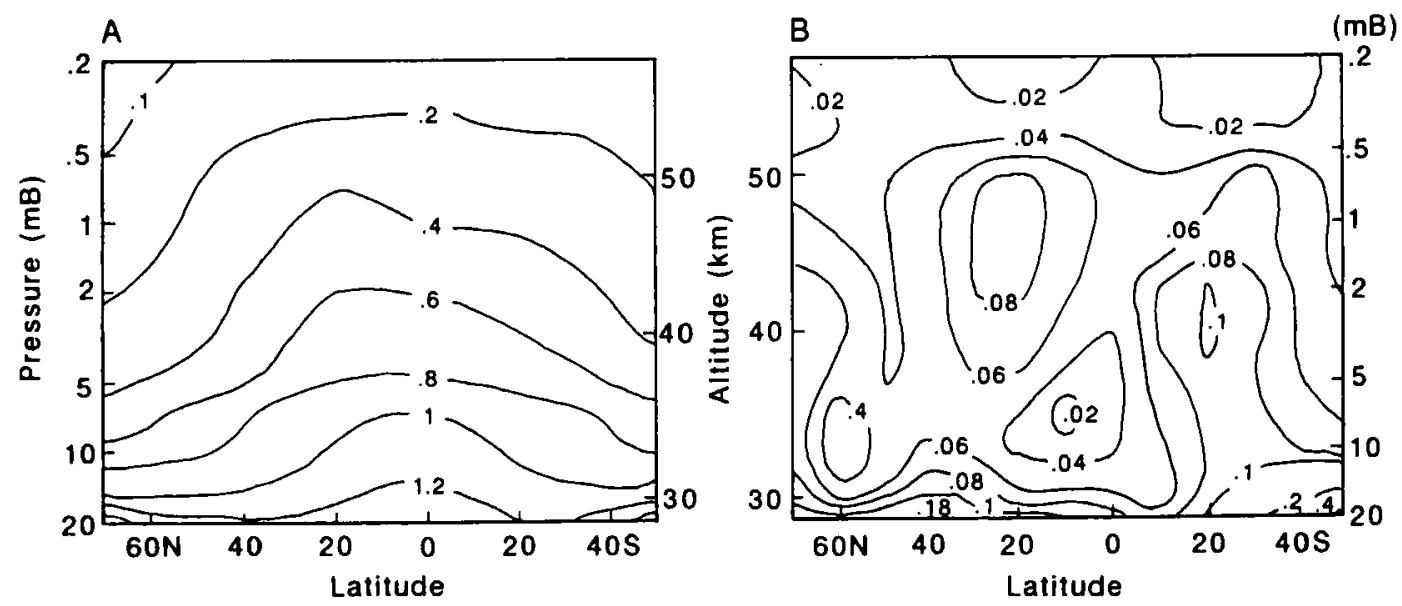

Fig. 3. As in Fig. 2 but of $\mathrm{CH}_{4}$ (ppmv). 

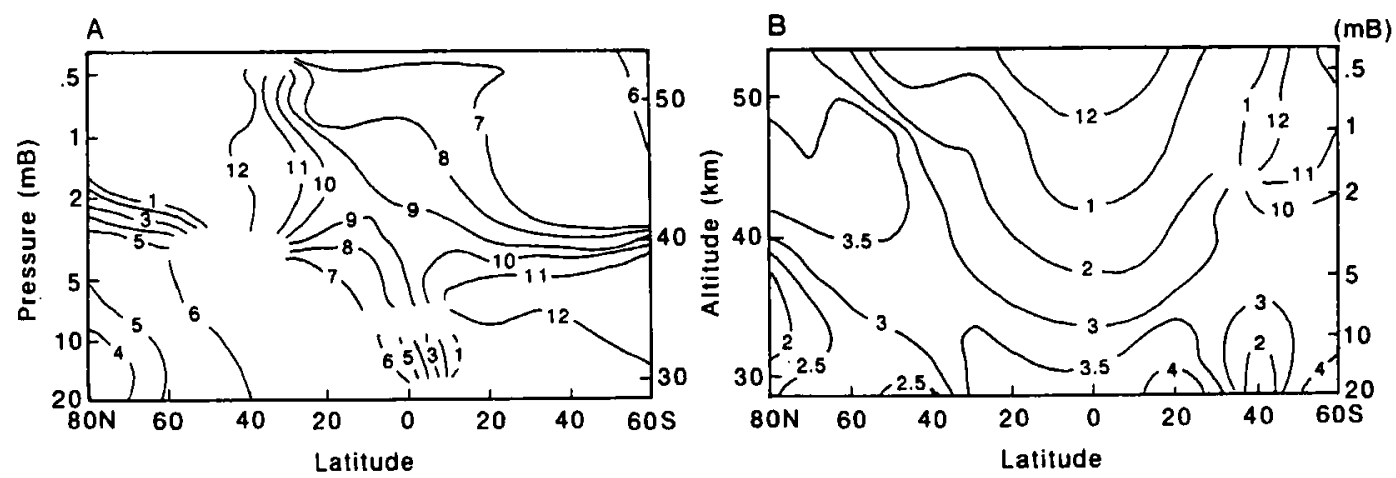

Fig. 4. The phase (time of maximum, month) of (A) the annual and (B) serniannual harmonics of $\mathrm{O}_{3}$.
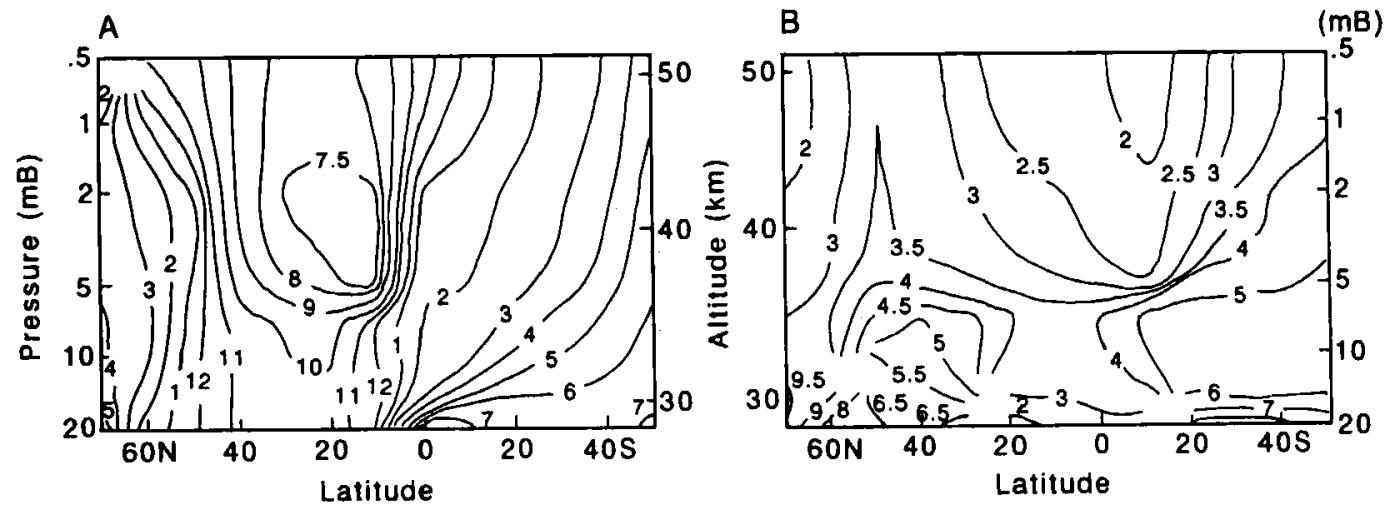

Fig. 5 . As in Fig. 4 but of $\mathrm{N}_{2} \mathrm{O}$.
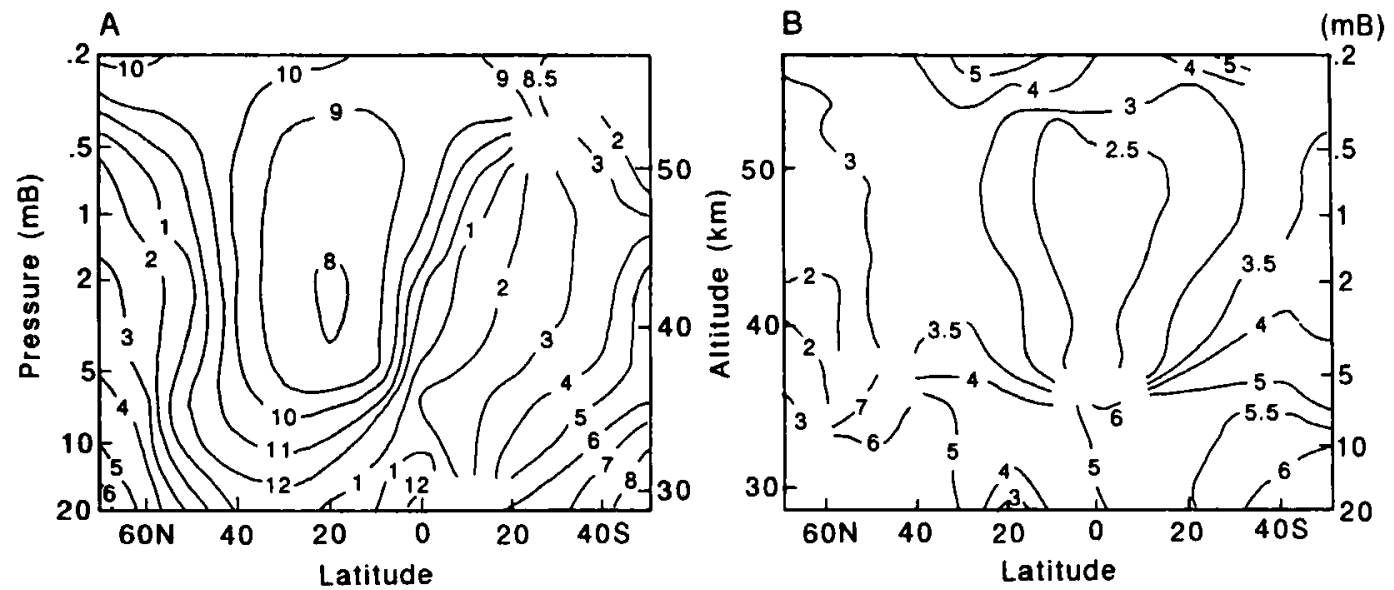

Fig. 6. As in Fig. 4 but of $\mathrm{CH}_{4}$. 

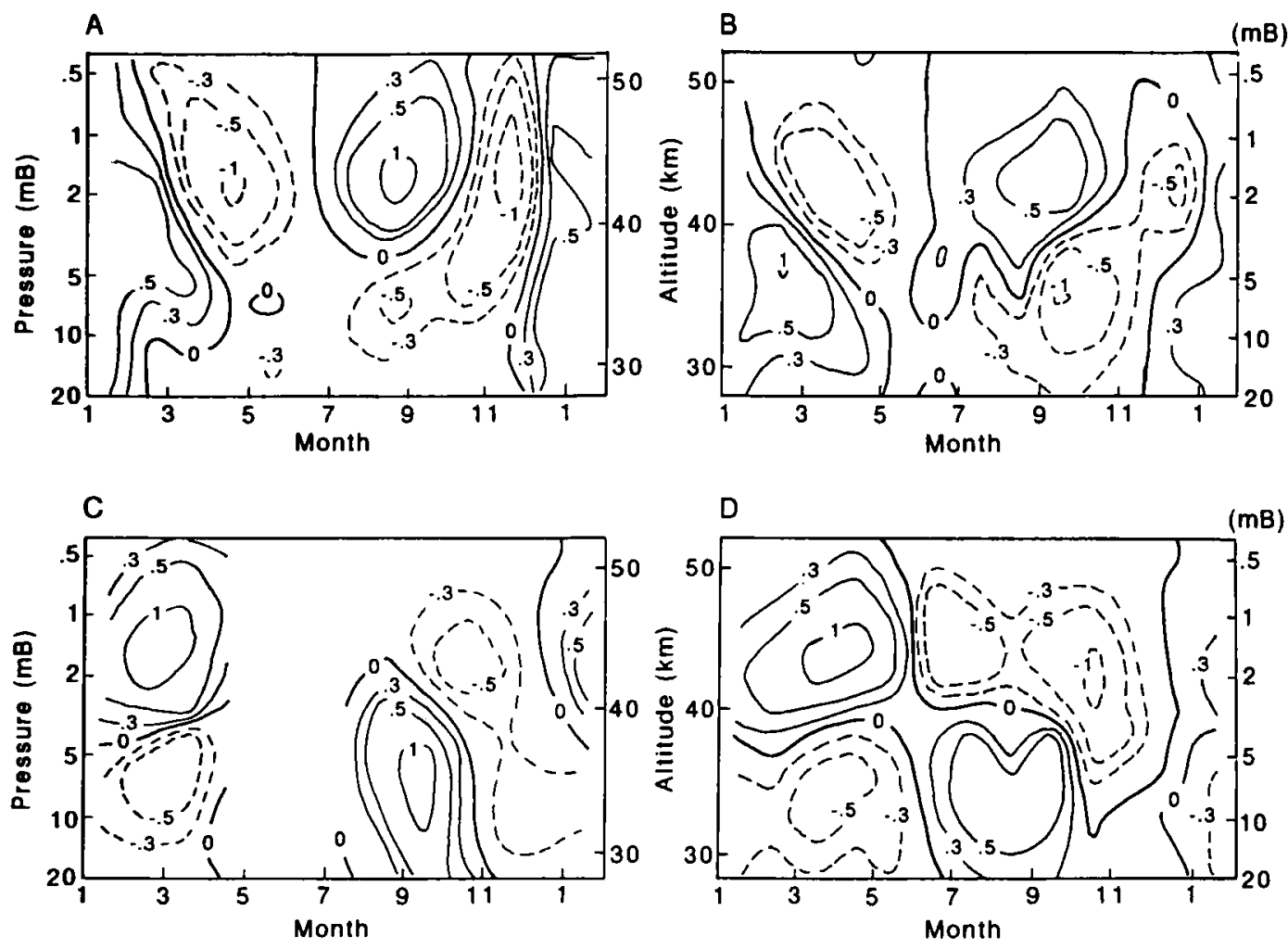

Fig. 7. Altitude-time cross sections of month-to-month changes of $\mathrm{O}_{3}$ (ppmv/month) at (A) $70 \mathrm{~N}$, (B) $50 \mathrm{~N}$, (C) $70 \mathrm{~S}$ and (D) $50 \mathrm{~S}$.

the MMCs of the $\mathrm{O}_{3}$ mixing ratios at $70 \mathrm{~N}, 50 \mathrm{~N}$, $70 \mathrm{~S}$ and $50 \mathrm{~S}$. Figs. 8 and 9 show the MMCs of the $\mathrm{N}_{2} \mathrm{O}$ and $\mathrm{CH}_{4}$ at $70 \mathrm{~N}, 50 \mathrm{~N}$ and 50S. Zero lines in the figures correspond to local time extrema (maxima or minima). The ozone annual cycle in the SH extratropical latitudes is characterised by opposite ozone changes in the upper and middle stratosphere during almost the entire year, except spring (Fig. 7). Unlike in the SH, opposite ozone changes in the upper and middle stratosphere in the NH extratropical latitudes are only seen in summer, in winter ozone increases at all altitudes. In spring the ozone increase continues in the middle stratosphere of the NH high latitudes, while in the upper stratosphere the process of increase is changed to the process of decrease. This causes the regime of maximum ozone mixing ratios to propagate downward in late winter to spring (see zero isoline in Fig. 7A). A similar feature of the downward propagation of the maximum values of ozone mixing ratios is also seen in spring at the NH middle latitudes (Fig. 7B) and the SH high latitudes (Fig. 7C). Note that the semiannual variation is more evident in the upper stratosphere in the $\mathrm{NH}$ extratropical latitudes than in the SH extratropical latitudes.

Distinct semiannual variations (and, sometimes, variations of higher frequencies) are seen in the $\mathrm{N}_{2} \mathrm{O}$ MMCs as well (Fig. 8). It should be noted that although the semiannual harmonic does not dominate in the annual cycles of the species in the most parts of the stratosphere, the strength of increase and decrease processes is often of the same order for different increase and decrease episodes (but duration of the episodes can be different, see Figs. 7 and 8 ).

The $\mathrm{N}_{2} \mathrm{O}$ annual evolution at $70 \mathrm{~N}$ (Fig. 8A) is characterised by a strong increase in the mixing ratios during winter and early spring but by decrease during the rest of year (except the two short-term increase episodes in summer and autumn). At lower levels the decrease is seen in mid-winter. Note that the spring maximum propagates from top to bottom. At 50N (Fig. 8B) 
the winter increase is still retained above $10 \mathrm{mb}$, but at lower levels it changes into a strong decrease. The decrease continues throughout the considered stratosphere till summer and then changes into increase, which is followed by the autumn decrease. The MMCs at $50 \mathrm{~S}$ show certain similarities to that at $50 \mathrm{~N}$ (after six month shift). However, there is an important difference: at $50 \mathrm{~N}$ the $\mathrm{N}_{2} \mathrm{O}$ increase above $10 \mathrm{mb}$ occurs in midwinter, while at $50 \mathrm{~S}$ the similar increase occurs in early spring.

The $\mathrm{CH}_{4} \mathrm{MMCs}$ in the upper stratosphere (Fig. 9) are in qualitative agreement with the $\mathrm{N}_{2} \mathrm{O}$ MMCs, although there are large quantitative differences there. A great difference is seen between the $\mathrm{N}_{2} \mathrm{O}$ and $\mathrm{CH}_{4} \mathrm{MMCs}$ at low levels. This will be discussed below.

Fig. 10 shows the latitude-time cross sections of the ozone MMCs at $3 \mathrm{mb}$ and $15 \mathrm{mb}$ correspondingly. The MMCs in the extratropical latitudes of the two hemispheres at $3 \mathrm{mb}$ are roughly anti symmetric (or symmetric because of the presence of the semiannual variation) about the equator, with periods of increase during mid-winter to mid-spring and during mid-summer to midautumn, and with a decrease during the rest of a year. At higher levels, however (for example, at the $1.5 \mathrm{mb}$ level, not shown, where the ozone MMCs have maximum values in the upper stratosphere; see Fig. 7), the ozone MMCs in the extratropical latitudes of the two hemispheres becomes asymmetric: unlike in the $\mathrm{NH}$, there is no any winter-to-spring ozone increase there in the SH. At the lower level, at $15 \mathrm{mb}$, the ozone MMCs in the extratropical latitudes are roughly antisymmetric about the equator (Fig. 10B). There are important interhemispheric differences, however, especially at high latitudes. First, in the northern polar region the ozone content increases during the winter period, while in the southern polar region the increase occurs in spring. The lag of the ozone increase process at the polar latitudes relative to the lower latitudes is also exhibited. Second, the distinctive difference in ozone springtime evolution is noted in the NH between the polar and middle latitudes: ozone continues to increase in the middle latitudes, but decreases in the polar region. Such opposite changes in the NH polar and middle latitudes are also seen in Fig. 7A and B. In the SH the similar feature, but of shorter duration and less intensity, is noted in early summer. Besides, the boundary between the opposite ozone changes shifts in the
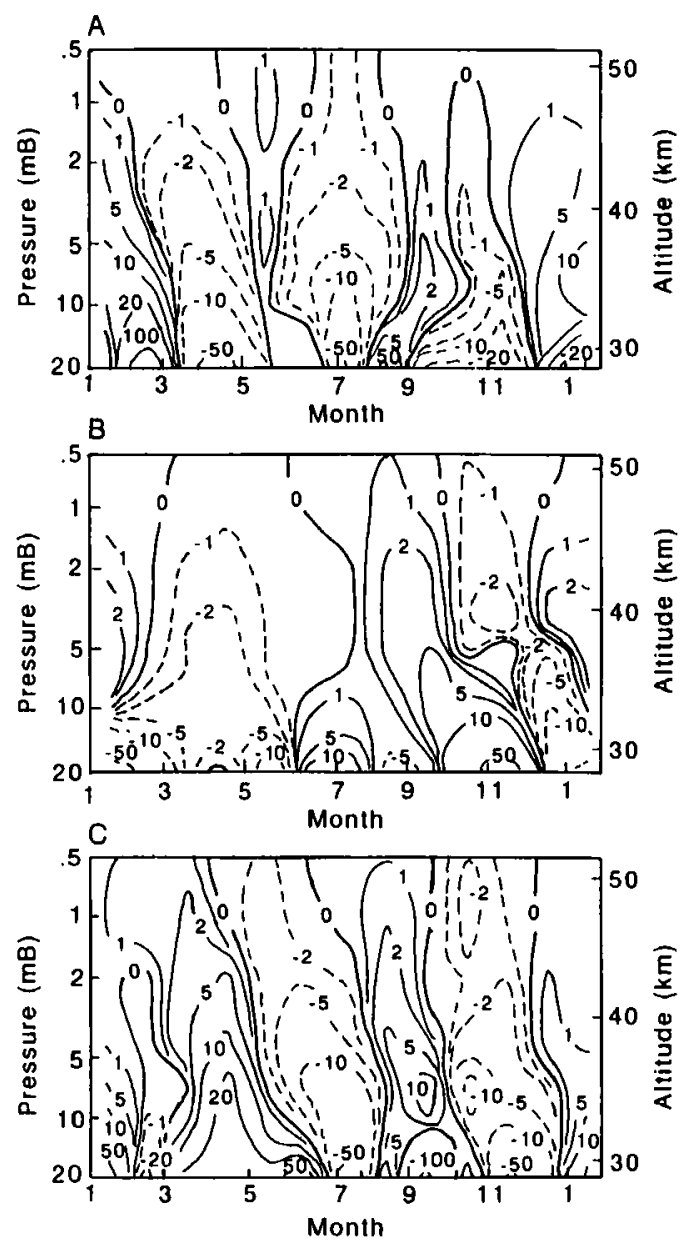

Fig. 8. Altitude-time cross-sections of month-to-month change of $\mathrm{N}_{2} \mathrm{O}$ (ppbv/month) at (A) $70 \mathrm{~N}$, (B) $50 \mathrm{~N}$, and (C) $50 \mathrm{~S}$.

SH to the lower latitudes (Fig. 10B) so that ozone variations in the southern polar region and at the adjacent latitudes are synchronous.

Figs. 11 and 12 show the latitude-time cross sections of the MMCs of $\mathrm{N}_{2} \mathrm{O}$ and $\mathrm{CH}_{4}$ at $3 \mathrm{mb}$ and $15 \mathrm{mb}$, correspondingly. The important feature in Figs. $11 \mathrm{~A}$ and $12 \mathrm{~A}$ is roughly symmetric patterns of isolines about the $\mathrm{NH}$ and $\mathrm{SH}$ subtropical latitudes during the period of the appropriate spring to autumn. The $\mathrm{N}_{2} \mathrm{O}$ increase, originating in the $\mathrm{NH}$ tropics in May, propagates during the following four months to the north and to the south. A similar propagation from the $\mathrm{SH}$ tropics is seen for the increase in the SH spring. However, during November to January the fast counter propagation from the $\mathrm{NH}$ high latitudes is seen, 
while no similar counter propagation is evident from August to September in the $\mathrm{SH}$ middle latitudes.

The $\mathrm{N}_{2} \mathrm{O}$ MMCs at $15 \mathrm{mb}$ (Fig. 11B) are roughly antisymmetric about the equator, with summer and autumn increase, and winter and spring decrease at middle latitudes. However, there is an important inter-hemispheric difference. The regime of the strongest increase in the $\mathrm{NH}$ has a tendency to propagate from the equator to the high latitudes, while this is not the case in the SH. This discrepancy is reflected in the phase dynamics of the annual harmonic in Fig. 5A. The important feature in Fig. 11B is also the opposite changes of $\mathrm{N}_{2} \mathrm{O}$ at the high and middle latitudes of the NH.

The MMCs of $\mathrm{CH}_{4}$ at the $15 \mathrm{mb}$ level (Fig. 12B) differ strongly from the MMCs of $\mathrm{N}_{2} \mathrm{O}$ (Fig. 11B). Rather the $\mathrm{MMCs}$ of $\mathrm{CH}_{4}$ at $15 \mathrm{mb}$ resemble the MMCs of $\mathrm{CH}_{4}$ at $3 \mathrm{mb}$ (after about a 6 month shift), with essential differences in the SH, however, where the MMCs at $15 \mathrm{mb}$ do not possess symmetry about the SH subtropical latitudes. Note that the regime of the autumn increase of $\mathrm{CH}_{4}$ at $15 \mathrm{mb}$ in the $\mathrm{SH}$ propagates from the low to middle latitudes. In the $\mathrm{NH}$ similar propagation is less evident. This interhemispheric difference is also reflected in the different rates of propagation of the phase of the annual harmonic in the $\mathrm{NH}$ and $\mathrm{SH}$ middle latitudes in Fig. 6B.

\section{Discussion}

The analysis made has revealed specific features in the annual cycles of $\mathrm{O}_{3}, \mathrm{~N}_{2} \mathrm{O}$ and $\mathrm{CH}_{4}$ in the stratosphere. The key to these features lies in knowing the circulation and photochemical processes. Solomon et al. (1986) and Holton \& Choi (1988) have shown that the diabatic circulation or the effective transport circulation explain main features of $\mathrm{N}_{2} \mathrm{O}$ and $\mathrm{CH}_{4}$ in the tropics and in the summer hemisphere. These circulations are qualitatively similar in that the solstices' upward velocity in the summer hemisphere and downward velocity in the winter hemisphere dominate. However, these two types of circulation are not adequate for describing transport of the species in winter and in spring, when transience of planetary waves has to be taken into account. It is well known that transient waves play an important
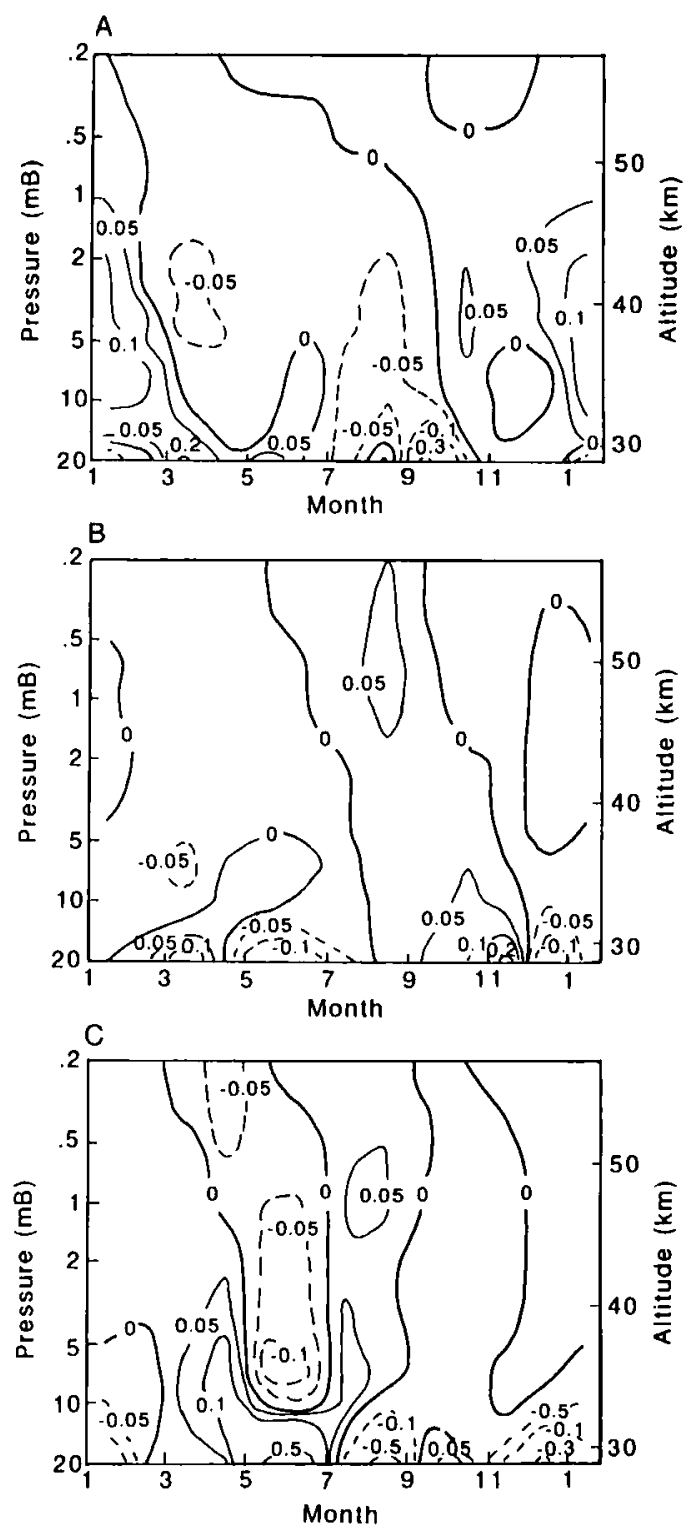

Fig. 9. As in Fig. 8 but of $\mathrm{CH}_{4}$ (ppmv/month).

role in transporting species (see e.g. Plumb 1979; Kurzeja 1983).

Features of the $\mathrm{N}_{2} \mathrm{O}$ and $\mathrm{CH}_{4} \mathrm{MMCs}$ seen in Figs. 8 and 9 are reflected in the effective transport velocity field deduced by Holton \& Choi (1988), so that decrease of mixing ratios usually occurs with downward transport and increase with upward transport (at subtropical latitudes hori- 

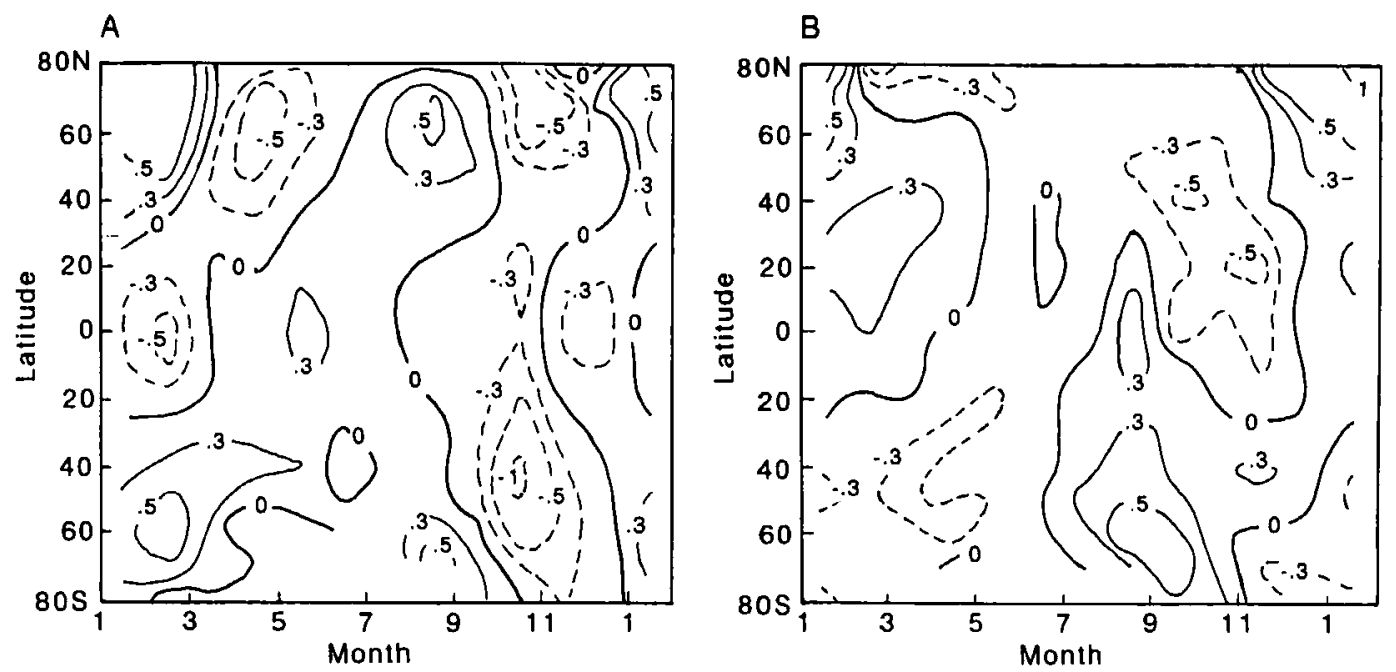

Fig. 10. Latitude-time cross sections of month-to-month changes of $\mathrm{O}_{3}$ (ppmv/month) at (A) $3 \mathrm{mb}$ and (B) $15 \mathrm{mb}$.
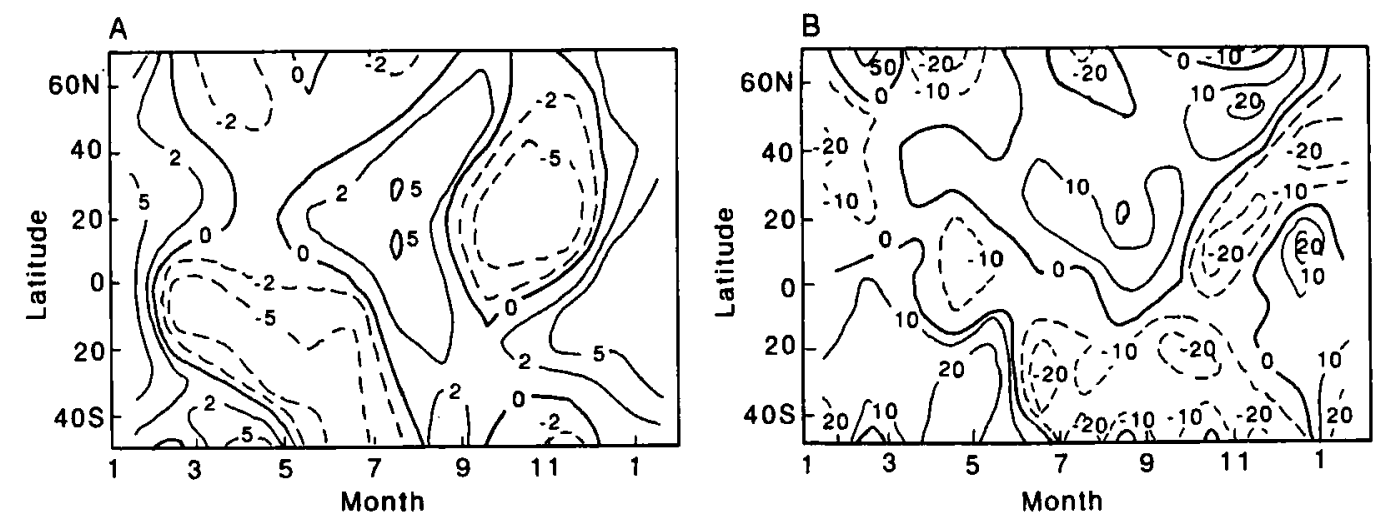

Fig. 11. As in Fig. 10 but of $\mathrm{N}_{2} \mathrm{O}$ (ppbv/month).
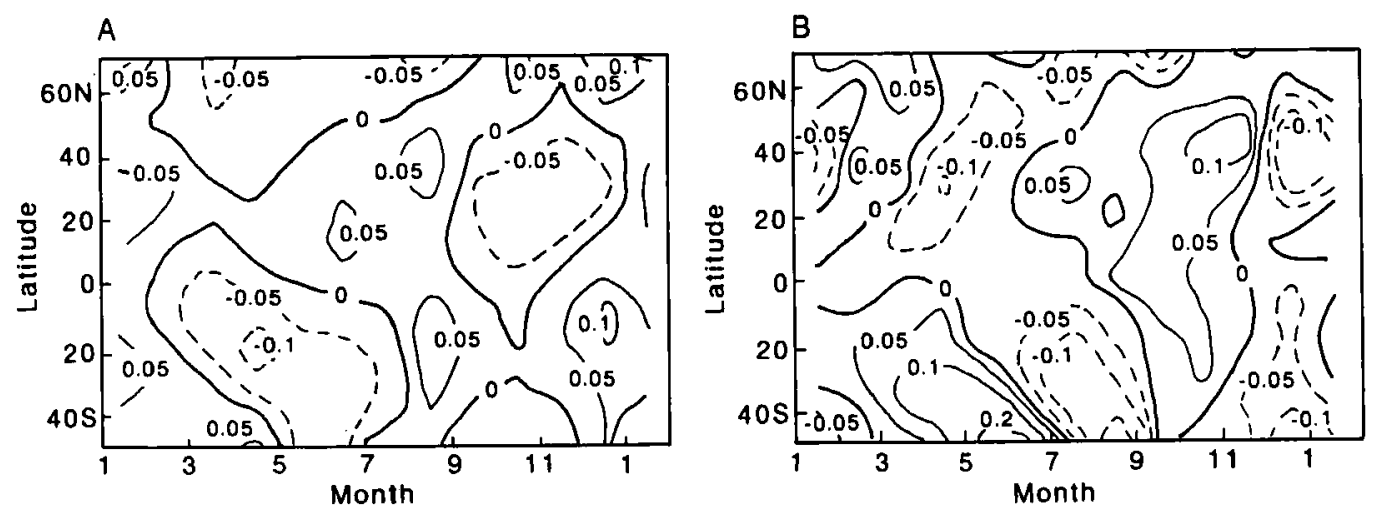

Fig. 12. As in Fig. 10 but of $\mathrm{CH}_{4}$. 
zontal transport can also affect the mixing ratios). The behaviour of the $\mathrm{N}_{2} \mathrm{O}$ and $\mathrm{CH}_{4}$ mixing ratios in the middle stratosphere at the $\mathrm{NH}$ high latitudes differs from that at the middle latitudes, being often the opposite (Figs. 11B and 12B). These opposite changes could be understood if one assumes the existence of a high latitude circulation cell. The $\mathrm{N}_{2} \mathrm{O}$ and $\mathrm{CH}_{4} \mathrm{MMCs}$ in the $\mathrm{NH}$ high latitude middle stratosphere, in winter for $\mathrm{CH}_{4}$ (Fig. 12B) but only from February to March for $\mathrm{N}_{2} \mathrm{O}$ (Fig. 11B), are consistent with such a circulation but require the subsiding arm of the circulation to be placed at middle latitudes. Note, however, that neither the effective transport circulation nor the residual mean circulation has any feature similar to this cell.

From summer to autumn the MMCs of $\mathrm{N}_{2} \mathrm{O}$ and $\mathrm{CH}_{4}$ in the middle and high latitudes of the NH middle stratosphere are often opposite to each other, but have positive values in the middle latitudes and negative values in the high latitudes. This discrepancy can be associated with the regime of the mixing ratio increase (due to upward motion in the summer hemisphere) propagating from the tropics (Figs. 11A and 12A), while at the high latitudes the decrease which began in spring continues (due to photochemical loss?). All these deductions are hypothetical and should be verified by calculations.

Essential interhemispheric differences in $\mathrm{N}_{2} \mathrm{O}$ and $\mathrm{CH}_{4}$ intra-annual variations have already been mentioned. The interhemispheric difference in phase characteristics in the middle stratosphere is particularly striking (Figs. 5 and 6). Big downward component in phase propagation of both the annual and semiannual harmonics in the $\mathrm{SH}$ extratropical latitudes, but rather horizontal propagation in the $\mathrm{NH}$ extratropical latitudes, are likely due to the predominant role of the residual meridional circulation in transporting the species in the $\mathrm{SH}$ winter stratosphere, while in the $\mathrm{NH}$ winter stratosphere, with its greater planetary wave activity, the horizontal eddy mixing is also important.

The difference between $\mathrm{N}_{2} \mathrm{O}$ and $\mathrm{CH}_{4}$ behaviour is also important. Although both species are produced in the troposphere and have potentially fairly long lifetimes as good tracers, they differ in the distribution and strength of sources as well as in altitude and latitude dependence of lifetimes. This results in different features of spatial distributions of $\mathrm{N}_{2} \mathrm{O}$ and $\mathrm{CH}_{4}$ and their variations, particularly in high latitudes. Characteristics of annual cycles of $\mathrm{N}_{2} \mathrm{O}$ and $\mathrm{CH}_{4}$ may therefore also be different because various circulation and photochemical mechanisms are displayed differently in $\mathrm{N}_{2} \mathrm{O}$ and $\mathrm{CH}_{4}$ evolution. Ozone has a quite different spatial distribution and a shorter photochemical lifetime, especially in the upper stratosphere, than $\mathrm{N}_{2} \mathrm{O}$ and $\mathrm{CH}_{4}$. Nevertheless, ozone intra-annual variations are generally in agreement with variations of $\mathrm{N}_{2} \mathrm{O}$ and $\mathrm{CH}_{4}$ in that they reflect the same dynamical processes. Opposite ozone changes in the upper and middle stratosphere in the two hemispheres in summer (Fig. 7) imply upward motions (cf. Fig. 1A). Similar opposite ozone changes (but of reversed sign) are realised in winter in the $\mathrm{SH}$ only. They could be related to downward motions. Quite different ozone behaviour in the NH in winter is associated with the horizontal pole-ward transport of ozone by planetary waves. Such a transport results in the winter-to-spring ozone increase seen in Fig. 7A and B and Fig. 10A and B. The effect of horizontal pole-ward transport of ozone is also seen in the $\mathrm{SH}$, but only during the relatively short period in spring (Fig. 7C and D and Fig. 10A and B). Moreover, in the upper stratosphere (at $1.5 \mathrm{mb}$ and higher), this effect disappears in the $\mathrm{SH}$, while the effect of the winter ozone increase in the $\mathrm{NH}$ is observed at least up to the $0.4 \mathrm{mb}$ level.

The striking interhemispheric difference in ozone intra-annual variations in the extratropical latitudes is known to be associated with the difference between the stratosphere dynamics of the $\mathrm{NH}$ and SH. It is manifested first of all as the interhemispheric differences in planetary wave activity. Planetary waves have the largest amplitudes during winter and through the spring in the $\mathrm{NH}$, but only in the spring in the $\mathrm{SH}$; moreover, they are about twice as intensive in the $\mathrm{NH}$ as in the SH (Geller \& Wu 1987). In their contribution to the ozone flux divergences, the stationary waves dominate in the NH. In the SH the stationary and transient eddy divergences of the ozone flux are of the same order (Geller et al. 1989). The stationary waves penetrate higher into the stratosphere in both hemispheres, however. This could explain the above-mentioned existence of the ozone increase in winter in the $\mathrm{NH}$ upper stratosphere and the absence of the similar increase in spring in the $\mathrm{SH}$.

The important role of horizontal eddy transport of ozone in the NH extratropical latitudes is also reflected in behaviour of the phase of the annual 
harmonic (Fig. 5A), which is consistent with the phase behaviour in Figs. 6A and 7A (implying the horizontal component in phase propagation).

The discrepancy between behaviours of middlestratosphere ozone in the NH polar and middle latitudes (Fig. 10B) is not understood. It could be explained if one suppose the existence of circulation cell with arising motions over the pole and subsiding motions at the middle latitudes. Besides, ozone fluxes due to such a circulation should not be compensated by eddy fluxes, as occurs in the case of stationary waves (Plumb \& Mahlman 1987). The transience of planetary waves in spring speaks in favour of non-compensating effect. This should certainly be verified by calculations and/or observations. In any case, the effect of polar-mid-latitude difference in ozone variations is supported by the polar-midlatitude difference in $\mathrm{N}_{2} \mathrm{O}$ and $\mathrm{CH}_{4}$ variations (see above).

The peculiarities of the $\mathrm{NH}$ polar region are also seen in behaviours of the phases of the semiannual harmonics (Figs. 4B, 5B and 6B). These are very likely not connected in any simple way to the tropical semiannual oscillation of zonal wind. The circulation associated with the tropical semiannual oscillation itself is likely to produce vertical motion in the extratropical latitudes (Gray \& Pyle 1986). On the other hand, the forcing occurring in the extratropical latitudes in winter hemisphere affects the circulation over the tropics (Solomon et al. 1986). Alternatively, the semiannual variations of the species in the northern polar region may be associated with the semiannual variation of planetary wave activity (Geller \& Wu 1987). The question of semiannual variations of atmospheric species in extratropical latitudes needs further investigation.

\section{References}

Geller, M. A. \& Wu, M. F. 1987: Troposphere-stratosphere general circulation statistics. Pp. 3-17 in G. Visconty \& R. Garcia (eds.): Transport Processes in the Middle Atmosphere. D. Reidel Publishing Company, Dordrecht, Holland.

Geller, M. A. \& Wu, M. F. \& Nash, E. 1989: Satellite data analysis of ozone differences in the Northern and Southern Hemispheres. Pure Appl. Geophys. 130, 263-275.

Gray, L. J. \& Pyle, J. A. 1986: The semi-annual oscillation and equatorial tracer distributions. Quart. J. R. Met. Soc. 112 , $387-407$.

Gruzdev, A. N., Karol, I. L., Kudryavtsev, A. P., Mokhov, I. I. \& Sitnov, S. A. 1991: Peculiarities of polar ozone annual course: Analysis of satellite and ozonesonde data and model results. Norsk Geolog. Tidsskr. 7I, 183-187.

Gruzdev, A. N. \& Mokhov, I. 1. 1988: Diagnostics of stratospheric ozone dynamics in annual course from satellite data. Issledovanie Zemli iz Kosmosa N 2, 3-10.

Holton, J. R. \& Choi, W.-K. 1988: Transport calculation deduced from SAMS trace species data. J. Atmos. Sci. 45, 1929 1939.

Jones, R. L. \& Pyle, J. A. 1984: Observations of $\mathrm{CH}_{4}$ and $\mathrm{N}_{2} \mathrm{O}$ by the Nimbus 7 SAMS: A comparison with in situ data and two-dimensional numerical model calculations. J. Geophys. Res. 89, 5263-5279.

Keating, M. \& Young, D. F. 1985; Interim reference ozone models for the middle atmosphere. Handbook for MAP 16. Pp. 205-229.

Kurzeja, R. J. 1983: The transport of trace chemicals by planetary waves in the stratosphere. Part 2: Transport of $\mathrm{O}_{3}$ and $\mathrm{N}_{2} \mathrm{O}$ by transient waves. J. Atmos. Sci 40, 2036-2054.

Mokhov, I. 1. 1985: Method of amplitude-phase characteristics for analysis of climate dynamics. Meteorol. Hydrol. 5, 14-23.

Plumb, R. A. 1979: Eddy fluxes of conserved quantities by small-amplitude waves. J. Atmos. Sci. 36, 1699-1704.

Plumb, R. A. \& Mahlman, J. D. 1987: The zonally averaged transport characteristics of the GFDL general circulation/ transport model. J. Atmos. Sci. 44, 298-327.

Solomon, S., Kiehl, J. T., Garcia, R. R. \& Grose, W. 1986: Tracer transport by the diabatic circulation deduced from satellite observations. J. Atmos. Sci. 43, 16013-1617.

Sun, C.-R. \& Leovy, C. 1990: Ozone variability in the equatorial middle atmosphere. J. Geophys. Res. 95, 13,829-13,849.

Taylor, F. W., Dudhia, A. \& Rodgers, C. D. 1987: Proposed reference models for nitrous oxide and methane in the middle atmosphere. Adv. Space Res. 7, (9)49-(9)62.

Wilcox, R. W., Nastrom, G. D. \& Balmont, A. D. 1977: Periodic variations of total ozone and its vertical distribution. J. Appl. Meseorol. 16, 290-298. 